\title{
Incentive theory for a participatory crowdsourcing project in a developing country
}

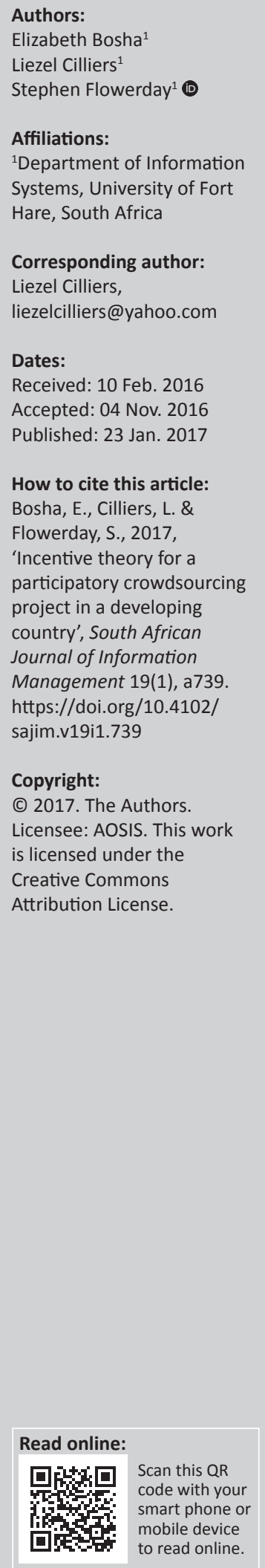

Authors:

Stephen Flowerday ${ }^{1}$

\section{Affiliations:}

1Department of Information Systems, University of Fort Hare, South Africa

\section{Liezel Cilliers,}

Published: 23 Jan. 2017

How to cite this article:

Bosha, E., Cilliers, L. \&

Flowerday, S., 2017

participatory crowdsourcing project in a developing Management 19(1), a739. :

Copyright: Licensee: AOSIS. This work is licensed under the Creative Commons
Background: Urbanisation has put enormous strain on the limited resources and services provided by city management. This means that the city must find new ways to manage their resources more effectively. One option is to collect data in a smart city from the citizens in order to make better decisions about resource management.

Objectives: The aim of this study was to provide a participatory crowdsourcing incentive model that can be used by the city of East London, South Africa, to collect information continuously from citizens in order to improve public safety in the city.

Method: This study made use of a quantitative approach to gather and analyse data. Data were collected using a questionnaire sent to all 91 East London citizens who had registered on the project website. The response rate was $81.3 \%$.

Results: A model was proposed that can be used by the city to increase the participation rate of citizens in smart city projects. Three factors: intrinsic, internalised-extrinsic and extrinsic, were identified as central to the incentive model.

Conclusion: The recommendation of the study is that city management can use the crowdsourcing participatory incentive model to ensure citizen participation in smart city projects.

\section{Introduction}

South Africa's urban population is growing, and it is anticipated that $80 \%$ of the South African population will be staying in cities by 2050 (Rand Daily Mail 2015). As more and more people are living in cities, the demand for the available resources is increasing. These resources include electricity, water, sanitation, road infrastructure and the ability to keep the city safe, such as adequate policing. These resources are finite and owing to budget constraints cannot be increased or even maintained properly (Washburn \& Sindhu 2010). This means that cities must search for more innovative ways of providing services to the increasing population making use of existing resources.

Some cities have decided to become 'smarter' in order to provide better management of the city. A smart city can be defined as 'a city that uses Information and Communications Technologies (ICT) to be more interactive, efficient and making citizens more aware of what is happening in the city' (Azkuna 2012:2). A smart city allows the city to improve resource management, which ensures that better decisions can be made about existing resources (Harrison \& Donnelly 2011). This results in a better quality of life for the citizens. Benefits of a smart city include citizens having better access to healthcare facilities and clean water and air as a result of reduced pollution and increased public safety (smart living) (Berst 2013).

The most important responsibility of city management is to ensure the quality of life and safety of their citizens. This can be accomplished by making use of technology that can monitor the activities that are happening in the city in real time. Citizens can report public safety issues to the city (known as participatory crowdsourcing), making use of mobile phones (Bartoli et al. 2013; Caragliu, Del Bo \& Nijkamp 2011). Cities need to collect large amounts of public safety data to use for predictive analysis in order to become more proactive. Currently, most cities rely on a reactive approach to public safety. Therefore, in order to collect public safety information, incentives can be used to encourage citizens to participate in such projects. The problem, however, is that there is currently no participatory crowdsourcing incentive model that allow city management to plan for continuous public safety data collection in a developing city.

This study discusses methods that can be used by the city to encourage citizens to participate in a smart city project by continuously reporting public safety issues they witness. Thus, the objective 
is to develop a participatory crowdsourcing incentive model that motivates citizens to continuously report public safety issues to the city.

The next section discusses the components of a smart city, followed by the different types of crowdsourcing. Then, citizen participation in smart city projects and the theoretical foundation of the paper, Incentive Theory, is discussed. The subsequent section describes the research methodology that was followed in this study. The paper concludes with an analysis and discussion section.

\section{Public safety in a smart city}

Public safety ensures that all citizens feel protected and safe in the city by focusing on collecting information to predict and respond faster to emergencies and threats (Bartoli et al. 2013). Information can be collected about natural disasters, accidents and deliberate harmful acts by citizens. In order to ensure safer living conditions for citizens, the city has to find better ways to manage its existing resources. This can be achieved by the following: (1) identifying and addressing public safety issues in the city; (2) being able to recover faster from natural disasters; and (3) collecting public safety information provided by citizens, thereby improving the quality of life for all (Nam \& Pardo 2011). A smart city approach makes use of participatory crowdsourcing which will allow city management to monitor the activities that are happening in the city (Caragliu et al. 2011; Figure 1).

According to Nam and Pardo (2011), in order for a city to become smarter, three components should be present: technology, people and institution (Figure 1). The first component is technology, which consists of hardware and software infrastructures, which allows for public safety information to be collected, processed and analysed in a city (Colldahl et al. 2013). Smart cities encourage the use of ICT to gain insights into what is happening in a city and enable decision-making based on the available information

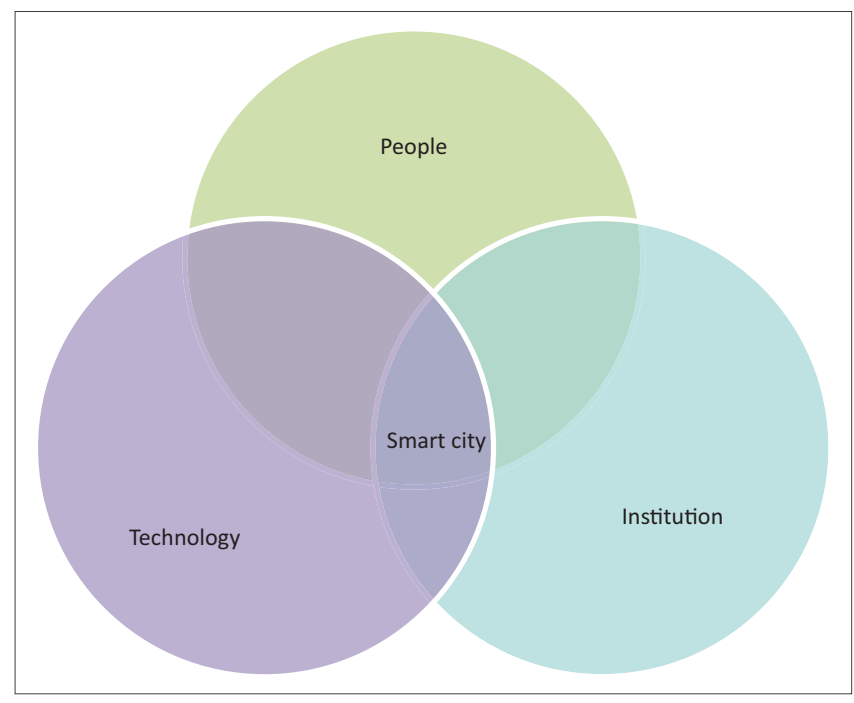

Source: Nam, T. \& Pardo, T.A., 2011, Conceptualizing smart city with dimensions of technology, people, and institutions, New York, ACM, pp. 282-291

FIGURE 1: Three key components of a smart city concept.
(Nam \& Pardo 2011). The type of technology used in a smart city includes sensors, which collect data from citizens making use of electronic devices such as mobile phones or tablets (Christin et al. 2011). Unfortunately, the cost of technology and infrastructure used in crowdsensing is prohibitive, which means that developing cities, such as East London, cannot afford to implement this solution. Sensors are also associated with privacy issues because individuals do not have control over when and what type of information is being collected (Shin et al. 2011). Apart from using sensors to collect information, citizens may also report any public safety information they witness by willingly volunteering it to city managers (participatory crowdsourcing) (Harrison \& Donnelly 2011). Making use of participatory crowdsourcing eliminates the problem of privacy because citizens voluntarily report any public safety information they witness. The second component of a smart city consists of people. According to Nam and Pardo (2011), people are the major component of a smart city because they enable communication with the city. People will assist in making a city smarter by being involved in the management of the city and by providing public safety information that will assist the city managers to better utilise the city's resources. Currently, there is no functional system in place that allows the citizens of East London to report public safety issues. The institution is the third component of a smart city. The institution consists of two components: the smart community, where citizens are empowered to make use of information technology to transform and support their individual and communal quests for well-being within a community, and smart growth, which makes use of technology to assist urban planners to make use of resources more efficiently in order to improve public safety (Nam \& Pardo 2011).

\section{Crowdsourcing}

Two different types of crowdsourcing have emerged from literature. These types of crowdsourcing allow for large amounts of data to be collected from the crowd (citizens). Data gathering allows citizens to be able to communicate with the city managers, and also allows the city to obtain information about the community and how people are living (Halder 2014). According to Doan et al. (2011), data can be gathered using either implicit methods (involuntary crowdsourcing) or explicit methods (participatory crowdsourcing). Implicit data collection methods make use of sensors to gather data, whereas explicit data collection methods request information from the crowd in order for the crowd to provide solutions (Doan et al. 2011). These two types of crowdsourcing are explained in the following section.

\section{Involuntary crowdsourcing}

Involuntary crowdsourcing is known in literature as opportunistic sensing or crowdsensing (Christin et al. 2011). Involuntary crowdsourcing requires less user involvement because it makes use of sensors to collect information automatically. This type of crowdsourcing allows for sharing 
of information about a citizen's immediate environment and experiences such as traffic information (Tomasic et al. 2014). The citizens of East London must agree to attach the devices that will record the data to their cellular phones. However, the citizens do not know when the data will be collected, which could be seen as an invasion of their privacy. The information collected from these sensors will then be processed in order to search for the required information.

Kaiserswerth (2010) reported that the city of Madrid has spent 30 million Euros to build a dashboard that is able to coordinate the police, fire, highway, hotline and ambulance units. This dashboard makes use of sensors across the city, such as traffic videos, surveillance cameras, maps with GPS data and the status and location of personnel that can be tracked through sensors in their mobile phones. This was made possible by the fact that smart technologies are able to improve both the availability and coordination of information during public safety events, thus enabling emergency services to minimise the risk and damage associated with these events.

\section{Participatory crowdsourcing}

Participatory crowdsourcing allows the crowd to provide public safety information willingly, without using any sensors. According to Cilliers and Flowerday (2014), participation is regarded as voluntary because participants can decide on what to report in terms of public safety issues they observe. Therefore, participatory crowdsourcing requires increased user involvement. With this type of crowdsourcing, the citizens can choose what they want to report and when they would like to report the data. This means that the privacy concerns mentioned in the previous section will not be relevant. Participatory crowdsourcing also has the advantage that existing cellular infrastructure can be used, which negates the cost of implementation of costly infrastructure.

In some countries, applications have been developed for individuals to inform the community if a citizen is in danger or if they witness any activity that might be a threat to their lives (Grass 2013). Examples of these countries include Haiti, Afghanistan and Chile, all of whom made use of crowdsourcing for disaster recovery by making use of the Ushahidi platform. The main objective of the Ushahidi platform was to communicate with affected citizens and to understand their community needs better. This platform allowed citizens to contribute any information related to natural or man-made disasters, thereby raising disaster awareness for other citizens (Meier 2012).

The use of participatory crowdsourcing in a city will help the city prepare for a particular situation affecting the safety of its citizens, as well as providing some insights on how to respond to an emergency situation and recover after the situation (Halder 2014). These applications ought to make it easy for public safety information to be collected continuously from the citizens.

\section{Incentive theory, the theoretical foundation}

The Incentive Theory is a motivational theory that focuses on rewards and motivation. The theory posits that people are motivated to perform tasks because of both external and intrinsic incentives (Cherry 2013). Incentives are a form of motivation that encourages people to do their best at a particular task (Brewer, Hollingsworth \& Campbell 1995). These incentives may vary depending on the task to be performed.

Sincero (2012) is of the view that the Incentive Theory differs from other theories of motivation in that it views the incentive as an item that attracts a person towards it. This means that in order for East London citizens to participate, incentives have to be offered to encourage citizens to provide public safety information to the city (Cherry 2013). In this project, the incentive was in the form of a better quality of life (intrinsic) and airtime (extrinsic), which was offered to citizens who provided public safety issues they witnessed.

\section{Types of incentives}

There are various types of incentives that can be used to motivate a person to perform a task or an activity. There are three types of incentives that are identified in literature; these include intrinsic, internalised-extrinsic and extrinsic incentives.

\section{Extrinsic incentives}

According to Gassenheimer, Siguaw and Hunter (2013), citizens can be motivated by extrinsic motivators, which require an economic advantage such as money or free products from a company. In a community, citizens may be extrinsically motivated by physical rewards such as money or airtime in order for them to provide public safety information.

Brewer et al. (1995) suggest that using extrinsic incentives is more effective than intrinsic incentives because the rewards are always positive and are likely to encourage citizens to continuously participate (Brewer et al. 1995). Examples of these extrinsic incentives include monetary and tangible non-monetary incentives. The effectiveness of these types of incentives may assist by motivating East London citizens to provide public safety information. The next section discusses intrinsic incentives.

\section{Intrinsic incentives}

Intrinsic incentives are based on the satisfaction a person feels after accomplishing an activity or task because it is enjoyable (Massung et al. 2013). Intrinsic incentives are not physical because they are based on a person's feelings. Examples of intrinsic incentives include enjoyment, interest, verbal recognition, feedback, curiosity and satisfaction. Intrinsic incentives allow citizens to view their involvement 
as a way of assisting the city to use resources more effectively, develop relationships with other citizens and also as a way of enjoyment. Intrinsically motivated citizens are most likely to share information with the public safety crowdsourcing project.

Some citizens obtain satisfaction from the action of providing public safety information to the city. Thus, external rewards are not required in order to motivate these citizens (Massung et al. 2013). This is because citizens are motivated by the feeling of accomplishment they acquire after reporting public safety issues and also because they will experience a better quality of life.

Nov, Naaman and Ye (2009) developed a model that attempts to explain an individual's willingness to participate in a community by providing or sharing information. This model states that motivation to participate in a community is dependent on an individual's willingness to participate in community matters (Nov et al. 2009). This means that the more a person is willing to participate, the more motivated they are.

Figure 2 illustrates that there could be various intrinsic reasons why citizens participate by reporting public safety information in a community. These reasons result in increased citizen participation. The next section discusses internalisedextrinsic incentives.

\section{Internalised-extrinsic incentives}

Internalised-extrinsic incentives refer to citizens who use their contributions to gain or to improve their reputation in a community with the intention of teaching or influencing other community members (Gassenheimer et al. 2013). In a city, this incentive enables residents to provide their views on public safety matters to the city. Citizens feel that they have participated or have control over how their safety is managed in the city. These incentives enable citizens to take ownership regarding public safety services that are available to all. The next section discusses methodology.

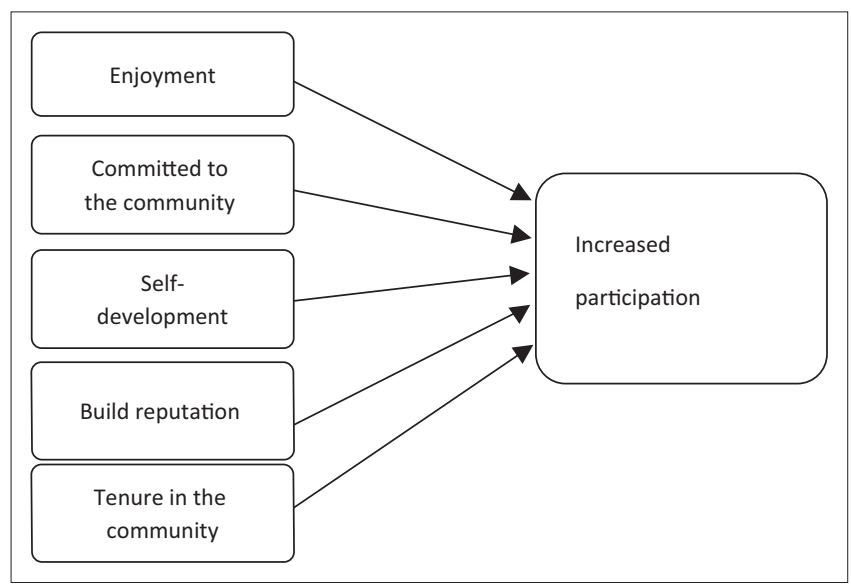

Source: Nov, O., Naaman, M. \& Ye, C., 2009, 'Analysis of participation in an online photosharing community: A multidimensional perspective', Journal of the American Society for Information Science and Technology, Paris, Wiley, 1-12

FIGURE 2: Citizen community participation model.

\section{Research methodology}

This study made use of a positivist paradigm and quantitative data collection method (Collis \& Hussey 2009). In this study, a literature review was used to identify the categories of the questionnaire and general insight into the research problem.

A pilot study was conducted in order to validate the questionnaire for user friendliness and ease of use. The feedback was taken into consideration and was included in the final questionnaire. Ethical approval was granted from the University Research Ethics Committee (UREC).

Participants were required to register on the project's website. A total of 91 citizens registered on the website after which they could report public safety issues via the Public Safety Smart City project (PCSS) toll-free number and a mobile site. The airtime incentive was awarded only to public safety reports that were complete, and an online questionnaire was sent to all 91 participants to investigate their reasons for participating. Seventy-four participants responded to the questionnaire. The response rate for this project was considered to be acceptable at $81.3 \%$. The reasons for such a high response could be that people wanted to improve city, or in order to receive the airtime incentive. Only 61 of the 74 questionnaires were found to be complete. In other words, $17.5 \%$ of the questionnaires collected could not be used. The questionnaire was hosted online and technical problems such as poor network connectivity or slow processing of devices could have influenced the completion rate of the questionnaires.

Quantitative data were collected from a questionnaire. The questionnaire comprised four sections. The first section asked for the demographics of the participants (age, gender). The rest of the sections represented the intrinsic, internalisedextrinsic and extrinsic factors. The intrinsic, internalisedextrinsic and the extrinsic sections included two, three and four questions, respectively. Cronbach's alpha coefficient was used in this project to determine the reliability of the factors identified in the model. The factors that were used in this project include intrinsic, internalised-extrinsic and extrinsic factors. The intrinsic, internalised-extrinsic and extrinsic factors had Cronbach's alpha coefficients of 0.69 , 0.62 and 0.58 , respectively. The values of 0.70 and above represent a good level of reliability, whereas values between 0.50 and 0.69 are considered to have an acceptable level of reliability (Pallant 2010). These three factors can thus be considered to have an acceptable level of reliability. Quantitative data were analysed making use of SPSS V22, descriptive statistics (mean, median) and inferential statistics.

\section{Results}

This study sample consisted of $54.1 \%$ female and $45.9 \%$ male participants. This shows that participation between males and females was almost equal. Both males and females were aware of the Public Safety Smart City Project and therefore reported issues they witnessed. 
Spearman correlation was conducted to test for the direction and strength of relationship between perceived usefulness and other variables (Figure 3). Intrinsic factors were found to be most important to increase the participation level of citizens in a smart city project. Participants found the project to be useful in terms of reporting public safety issues they witnessed. Therefore, participants indicated that they are willing to continuously provide information on public safety issues they witness.

\section{Ethical consideration}

Ethical clearance was granted by the University of Fort Hare's Research Ethical Committee. The ethical clearance number is FLO041SPID01.

\section{Participatory crowdsourcing incentive model}

The model for this project was derived from the findings of the literature review, observations and questionnaire incorporating the Incentive Theory. Spearman correlation was used to test for the direction and strength of the relationship between increased participation and other variables. The figures in the model represent the relationship between variables, whereby weak/small ( $r=0.10$ to 0.29 ), medium ( $r=0.30$ to 0.49$)$ and strong/large $(r=0.50$ to 1.0$)$ (Pallant 2007) relationships are presented. The model is presented in Figure 3.

The model identifies factors that encourage citizens to provide information on public safety issues they witness to the city continuously. These factors are discussed in the next sections.

\section{Intrinsic factors}

Intrinsic incentives provide the internal feeling that a citizen feels after reporting public safety issues they observe (Brewer et al. 1995). In order for the Public Safety Participatory Crowdsourcing Incentive Model to be effective, the city has to ensure that they offer intrinsic incentives for citizens that are intrinsically motivated. These factors include: a useful way to report public safety issues, usefulness of the project,

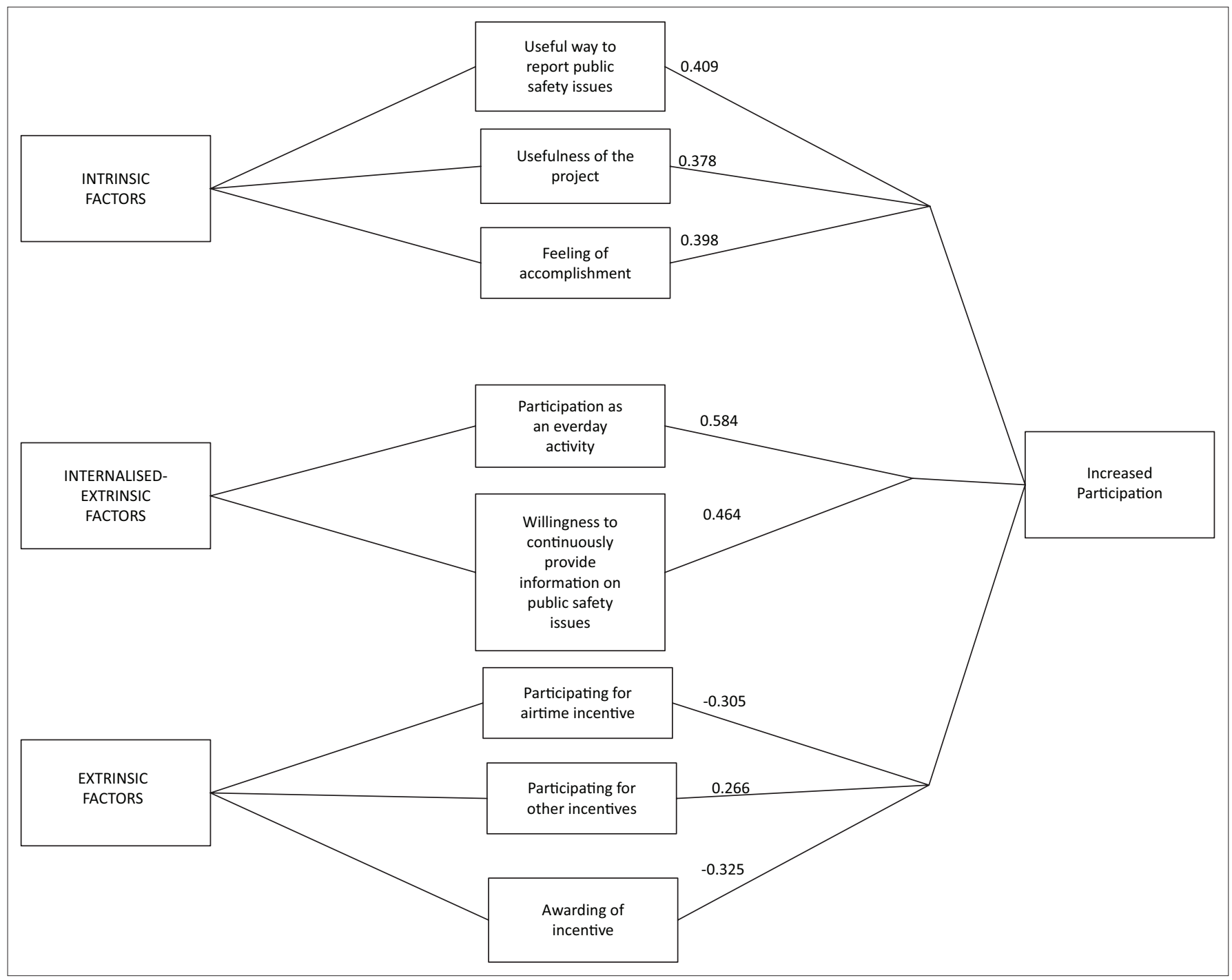

FIGURE 3: Participatory Crowdsourcing Incentive Model. 
feeling of accomplishment and a city that responds to their reports.

\section{Useful way to report public safety issues}

This factor focuses on the value of the crowdsourcing system to participants. According to Gassenheimer et al. (2013), citizen involvement in city matters will allow them to use the crowdsourcing system to report issues they observe. This results in increased participation as continuous public safety information will be provided by citizens. Figure 3 illustrates a medium relationship, whereby participants indicated that participation increased because it was a useful way to report public safety issues. Therefore, it is necessary for the city to involve citizens by reporting public safety issues.

\section{Usefulness of the project}

This factor focuses on how the project was useful to citizens in terms of reporting public safety issues. Participants found this project to be useful in terms of reporting issues in order to make the city safer because previously there was no effective crowdsourcing system in place that allowed them to communicate these issues to the city. The Public Safety Smart City project made it easy to report public safety issues, thereby increasing citizen participation. This is because participants used the project's toll-free number and the mobile site which worked effectively by continuously collecting information. In 2015, East London city had an increase in recorded crime rates (7963 from 7858 crimes in 2014); therefore, the project was useful as it allowed citizens to report these crimes (Massung et al. 2013).

\section{Feeling of accomplishment}

According to the Incentive Theory, a person performs a task in order to be awarded an incentive in the end (Cherry 2013). In this case, citizens reported public safety issues in order to enjoy the feeling of accomplishment. Participants believed that the public safety project made it possible for them to provide information on the public safety issues they witnessed, thus leading to increased feelings of accomplishment. Feeling of accomplishment is important for intrinsically motivated participants who would like to provide information on public safety issues they witness. This factor is associated with the satisfaction a participant acquires after providing public safety information with the help of a well-functioning Participatory Crowdsourcing Model. The next section discusses internalised-extrinsic factors.

\section{Internalised-extrinsic factors}

Internal-extrinsic factors allow participants to take part in an activity in order to improve their reputation and to influence other citizens to make a difference in the community (Gassenheimer et al. 2013). This includes two factors that will encourage continuous public safety collection. These factors are participation as an everyday activity and willingness to provide public safety information. The next section discusses everyday activity.

\section{Participation as an everyday activity}

Everyday activity is one of the factors that ensure that the Public Safety Participatory Crowdsourcing Incentive Model is effective. This allows for the city to gather public safety information continuously from citizens. Collecting information on public safety issues regularly will assist the city to update or create new policies and operational procedures that will help reduce these issues, thereby making the city safer (Harrison \& Donnelly 2011).

\section{Willingness to report public safety issues continuously}

This factor is important for the Participatory Crowdsourcing Model because it allows for public safety data to be collected from citizens continuously. The model suggests that the willingness to provide public safety issues continuously is more likely to affect citizen participation. Citizens will provide public safety information they observe regardless of whether they are being offered incentives or not, resulting in continuous public safety information being collected from citizens. The next section discusses extrinsic factors.

\section{Extrinsic factors}

Extrinsically motivated people perform an activity in order to be awarded an extrinsic incentive. Extrinsic factors consist of incentive motivation, participating for incentives. The next section discusses extrinsic motivation factors.

\section{Participating for airtime incentive}

The model illustrates that incentive motivation is less likely to be associated with increased participation. This means that majority of the participants did not report in order to be awarded the airtime incentive. Brabham (2012) states that various interviews and surveys have been conducted in order to find out what motivates people to participate in a crowdsourcing project, and it was found that there is no single motivator that encourages all participants. Therefore, the city of East London should incorporate incentives to encourage those participants who are encouraged by incentives.

Participating for other incentives: Literature suggests that participants prefer different incentives, depending on the person. Some prefer monetary incentives and some prefer non-monetary incentives (e.g. gift cards). The model found some relationship between extrinsic incentives and citizen participation. This indicates that participation levels were increased because some citizens reported in order to be awarded the airtime incentive.

\section{Awarding of incentive}

As mentioned in literature, some participants take part in an activity in order to be awarded for their performance. As illustrated in Figure 3, this factor had a negative medium relationship. This indicates that for some participants, the level of participation is not affected by the airtime they receive as their incentive. Thus, these citizens will provide 
public safety issues they witnessed even if they are not awarded incentives.

\section{Conclusion}

There are various public safety issues that are experienced by citizens as a result of urbanisation. In order to reduce these issues, the city can use participatory crowdsourcing to gather public safety information in a real-time and continuous basis. The city can make use of incentives as a way of encouraging citizen participation. This study explained how different types of incentives motivate citizens. The main aim for this study was to develop a crowdsourcing model that will assist the city in the continuous collection of data. The Public Safety Participatory Crowdsourcing Incentive Model was developed, and it identified different factors that that may be used to encourage citizens to continuously report public safety issues. Therefore, to improve the continuous data collection in a smart city project, the following motivators are important: intrinsic, internalised-extrinsic and extrinsic factors. The city can make use of these factors in order to keep collecting public safety reports continuously, thereby improving the quality of life of citizens.

\section{Limitations and recommendations for future research}

One of the limitations of this study was the small population size that completed the questionnaire which limits the generalisability of the results and the subsequent model. However, as the study made use of a case study approach, the results can be considered a reflection of the factors that will motivate the citizens of East London to participate in the smart city project. This study only focused on participatory crowdsourcing; crowdsensing and the use of sensors were not included in this project as participants were required to report. Using sensors could allow for more public safety data to be collected from citizens. The model developed in this study can be applied to other smart living aspects (such as health care and transport) besides public safety. Future research could focus on the appropriate incentive systems. This will guide future projects on the right or correct incentives that should be offered to participants for completing a task.

\section{Acknowledgements}

This project was funded by the National Research Foundation (NRF) and IBM and based on the research supported in part by IBM, the NRF of South Africa and the citizens of East London. The authors acknowledge that the opinions, findings, and conclusions or recommendations expressed in this article are those of the authors and that IBM and the NRF accept no liability whatsoever in this regard.

\section{Competing interests}

The authors declare that they have no financial or personal relationship(s) that may have inappropriately influenced them in writing this article.

\section{Author's contributions}

E.B. completed the research study in fulfilment of her degree requirements, and L.C. and S.F. made conceptual contributions to the project.

\section{References}

Azkuna, I., 2012, Smart cities study: International study on the situation of ICT, innovation and knowledge in cities, The Committee of Digital and Knowledgebased Cities of UCLG, Bilbao.

Bartoli, G., Fantacci, R., Gei, F., Marabissi, D. \& Micciullo, L., 2013, 'A novel emergency management platform for smart public safety', International Journal of Communications Systems 28, 928-943. http://dx.doi.org/10.1002/dac.2716

Berst, J., 2013. Smart cities readiness guide, Seattle, WA: Smart Cities Council.

Brabham, D.C., 2012, 'Motivations for participation in a crowdsourcing application to improve public engagement in transit planning', Journal of Applied Communication Research 40(3), 307-328. http://dx.doi.org/10.1080/00909882. 2012.693940

Brewer, E.W., Hollingsworth, C. \& Campbell, A., 1995, 'Incentive motivation psychology: An exploration of corrective learning behaviour', Journal of the Southeastern Association of Educational Opportunity Program Personnel, XIV(1), 33-56.

Caragliu, A., Del Bo, C. \& Nijkamp, P., 2011, 'Smart cities in Europe', Journal of Urban Technology, 18(2), pp.65-82.

Cherry, K., 2013, The incentive theory of motivation: Are actions motivated by a desire for rewards?, viewed 2 July 2014, from http://psychology.about.com/od/ motivation/a/incentive-theory-of-motivation.htm

Christin, D., Reinhard, A., Kanhere, S.S. \& Hollicka, M., 2011, 'A survey on privacy in mobile participatory sensing applications', The Journal of Systems and Software 84, 1928-1946. http://dx.doi.org/10.1016/j.jss.2011.06.073

Cilliers, L. \& Flowerday, S., 2014, Information security in a public safety, participatory crowdsourcing smart city project, London, World CIS, pp. 1-5.

Colldahl, C., Frey, S. \& Kelemen, J.E., 2013, Smart cities: Strategic sustainable development for an urban world, Blekinge Institute of Technology, Karlskrona.

Collis, J. \& Hussey, R., 2009, Business research, 3rd edn., Palgrave Macmillan, London, UK.

Doan, A., Franklin, M.J., Kossma, D. \& Kraska, T., 2011, 'Crowdsourcing applications and platforms: A data management perspective', VLDB Endowment 4(12), 1508-1509.

Gassenheimer, J.B., Siguaw, J.A. \& Hunter, G.L., 2013, 'Exploring motivations and the capacity for business crowdsourcing', Academy of Marketing Science 2013(3), 205-216. http://dx.doi.org/10.1007/s13162-013-0055-8

Grass, J., 2013, Crowdsourcing our safety, viewed 20 October 2014, from http:// whartonmagazine.com/blogs/crowdsourcing-our-safety/

Halder, B., 2014, 'Evolution of crowdsourcing: Potential data protection, privacy and security concerns under the New Media Age', Digital Democracy and E-Government 1(10), 377-393.

Harrison, C. \& Donnelly, I.A., 2011, A theory of smart cities, International Society for the Systems Sciences (ISSS), Hull, UK, pp. 1-15.

Kaiserswerth, M., 2010, Creating a smarter planet, one collaboration at a time, IBM, Zurich.

Massung, E., Coyle, D., Cater, K.F., Jay, M. \& Preist, C., 2013, Using crowdsourcing to support pro-environmental community activism, Paris, ACM, pp. 371-380.

Meier, P., 2012, How crisis mapping saved lives in Haiti, viewed 17 November 2014, from http://voices.nationalgeographic.com/2012/07/02/crisis-mapping-haiti/

Nam, T. \& Pardo, T.A., 2011, Conceptualizing smart city with dimensions of technology, people, and institutions, New York, ACM, pp. 282-291.

Nov, O., Naaman, M. \& Ye, C., 2009, 'Analysis of participation in an online photosharing community: A multidimensional perspective', Journal of the American Society for Information Science and Technology, Paris, Wiley, 1-12.

Pallant, J., 2010, SPSS survival manual: A step by step guide to data analysis using SPSS, 4th edn., McGraw-Hill, New York.

Rand Daily Mail, 2015, New figures show staggering rate of urbanisation in SA, viewed 21 January 2016, from http://www.rdm.co.za/politics/2015/05/26/new-figuresshow-staggering-rate-of-urbanisation-in-sa

Shin, M., Cornelius, C, Peebles, D., Kapadia, A., Kotz, D. \& Triandopoulos, N., 2011 'AnonySense: A system for anonymous opportunistic sensing', Journal of Pervasive and Mobile Computing 7(1), 16-30. http://dx.doi.org/10.1016/j.pmcj.2010. 04.001

Sincero, S.M., 2012, Incentive theory of motivation, viewed 10 July 2014, from https:// explorable.com/incentive-theory-of-motivation

Tomasic, A., Zimmerman, J., Steinfeld, A. \& Huang, Y., 2014, Motivating contribution in a participatory sensing system via Quid-Pro-Quo, ACM, Baltimore, MD.

Washburn, D. \& Sindhu, U., 2010, 'Helping CIOs understand "Smart City" initiatives', Forrester 1(1), 1-17. 